\title{
Original Article \\ Evaluation of serum squamous cell carcinoma antigen as a novel biomarker for diagnosis of hepatocellular carcinoma in Egyptian patients
}

\author{
Hussein MM, Ibrahim AA, Abdella HM, Montasser IF, Hassan MI ${ }^{1}$ \\ Departments of Tropical Medicine and 'Diagnostic Oncology, Ain Shams University Cairo, Egypt
}

Correspondence to: Dr. Heba Mohammed Abdella, E-mail: hbabdella@yahoo.com

\begin{abstract}
BACKGROUND: Hepatocellular carcinoma (HCC) is the fifth most common malignancy in the world. In Egypt, HCC was reported to account for about $4.7 \%$ of chronic liver disease (CLD) patients. Squamous cell carcinoma antigen (SCCA) has been reported to be strongly expressed in HCC tissue hampering its extensive use in clinical practice. AlM: To evaluate the clinical usefulness of serum SCCA levels as a serological marker for early detection of HCC among high-risk patients compared to AFP. MATERIALS AND METHODS: The study comprised of three groups. Group A included 30 patients with CLD diagnosed based on clinical, laboratory, and ultrasonographical investigations; group B included 49 patients with HCC diagnostically confirmed by spiral CT, elevated alfafetoprotein (AFP), and/or liver biopsy; and group C, the control group, included 15 healthy subjects matched for age and sex. All groups were subjected to thorough history taking, full clinical examination, and laboratory investigations including liver functions, viral markers, and AFP and SCCA estimation using ELISA technique. RESULTS: This study revealed a highly significant difference between patients with HCC, CLD, and controls regarding serum SCCA levels $(5.138 \pm 7.689,1.133 \pm 0.516$, and $0.787 \pm 0.432 \mathrm{ng} / \mathrm{ml}$, respectively). SCCA level was persistently elevated in patients with HCC with normal AFP levels representing its useful role in early detection and follow-up of patients treated for HCC. The area under the curve (AUC) of SCCA was $0.869(95 \% \mathrm{Cl} 0.783-0.929)$, the cut-off value was established at $1.5 \mathrm{ng} / \mathrm{ml}$ with sensitivity of $77.6 \%$ and specificity of $84.4 \%)$. The difference between AUC of SCCA and that of AFP was 0.09 which mounted statistical significance. CONCLUSIONS: SCCA could represent a useful tool as a marker for detection of HCC.
\end{abstract}

Key words: Hepatocellular carcinoma, squamous cell carcinoma antigen, tumor markers

\section{Introduction}

H epatocellular carcinoma (HCC) is the fifth most common cause of cancer deaths worldwide. The incidence is rising, and is expected to increase by another $81 \%$ by 2020 primarily due to H CV epidemic. ${ }^{[1]}$

Egypt, like the Western countries, has an overall frequency of $2.3 \%$ among other types of cancer. ${ }^{[2]}$ There is an apparent increase in the number of $\mathrm{HCC}$ patients attending the various oncology centers in Egypt and all over the world. ${ }^{[3]}$ In 2001, HCC in Egypt was reported to account for about $4.7 \%$ of chronic liver disease (CLD) patients. ${ }^{[4]}$ In another study, in 2005, a remarkable increase from $4-7.2 \%$ was reported over a decade. ${ }^{[5]}$ Patients with advanced liver disease, particularly cirrhosis, are those at risk for HCC and should be screened every six months for its development. ${ }^{[6]}$

Currently, standard surveillance includes a combination of six monthly abdominal ultrasound scans and serum alpha fetoprotein (AFP) measurement, but this strategy does not reliably detect early disease. AFP may be elevated in $C L D$, especially in viral hepatitis, in the absence of HCC. The differential diagnosis of elevated AFP levels also includes gastric, biliary, and pancreatic cancers and germ cell tumors. ${ }^{[7]}$

The relatively poor sensitivity of conventional AFP as a marker has led to a search for more sensitive and specific markers. Other tumor markers include serum 
Des-gamma-carboxy prothrombin (DCP) that has been used for screening of HCC. The failure of hepatoma cells to express prothrombin carboxylase leads to a higher DCP serum levels. The sensitivity of DCP is better than that of AFP only in larger tumors and hence is of limited benefit in clinical practice. ${ }^{[8]}$

It has been reported that squamous cell carcinoma antigen (SCCA), a member of the high molecular weight family of serine protease inhibitors, is strongly expressed in a number of different epithelial cancers such as those of the cervix, lung, and head and neck, and so can be used as a clinical marker of these malignancies. ${ }^{[9]}$

O verexpression of SCCA variants (SCCA 1, SCCA2) has been reported in all surgically resected $\mathrm{HCC}$ specimens but in none of the normal control livers as detected by immunohistochemistry. ${ }^{[10]}$

The aim of this work was to evaluate the clinical usefulness of serum SCCA levels as a marker for early detection of $\mathrm{HCC}$ among high-risk patients compared to AFP as a known biomarker for diagnosis of HCC.

\section{Materials and Methods}

Patients attending the Tropical M edicine D epartment, Ain Shams U niversity, as well as the outpatient clinic for early detection of hepatic tumors (clinic of Ain Shams H epatoma Group), during May 2005 to March 2007 were evaluated. A part from obtaining a detailed clinical history, general and abdominal examinations were done for all the selected patients. The patients underwent laboratory investigations that included complete blood count and ESR, liver function tests, viral markers (H BsAg, HBCAbs, and HCVAbs), and determination of AFP levels by an ELISA technique. ${ }^{[11]}$ Abdominal ultrasonography to determine the liver size, echogenicity, presence of focal lesions (size, number, echogenicity), and portal vein (patency, diameter) was also done. Spiral triphasic abdominal CT scan was used to confirm the findings of abdominal ultrasonography and for studying of suggestive criteria for HCC (early enhancement in arterial phase, rapid washout in subsequent phases portovenous and delayed phases). If needed, liver biopsy and histopathological examination were done for patients with hepatic focal lesion detected by the ultrasound and missing the HCC criteria in spiral CT or with normal AFP.

Then the selected patients were set into two groups: group A consisting of 30 patients with chronic liver disease (CLD) diagnosed based on clinical, laboratory, and/or ultrasonographic examinations; and group B consisting of 49 patients with $\mathrm{HCC}$ confirmed by spiral triphasic CT scan, elevated AFP levels > 200, and/or liver biopsy. ${ }^{[12]}$

Fifteen age and sex matched healthy subjects were included in the control group, designated as group $C$. Their age ranged between 25-65 years (mean $48 \pm$ 12.3). There were seven men and eight women. All their laboratory data were within normal range. SCCA level[13] by ELISA according to the recommendations of the manufacturer was measured in the sera of the subjects in all three groups.

Exclusion criteria included patients with other suspected epithelial malignancies of cervix, lung, head and neck, metastatic liver tumors, and other types of CLD such as autoimmune hepatitis and primary biliary cirrhosis.

\section{Statistical Methods}

Analysis of the data was done using statistical program for social science (SPSS). The quantitative variables are described in the form of mean and standard deviation, while the qualitative variables are described in the form of frequency and percentages. U npaired t test (t value) was used to compare a quantitative variable between two independent groups in parametric data. $M$ ann Whitney test ( $Z$ value) was used instead of the $t$ test to compare a quantitative variable between two independent groups when data were nonparametric (SD $>25 \%$ of mean). Chi square test ( $X^{2}$ value) was used to compare a qualitative variable between two independent groups. Spearman correlation test (rho value) was used to rank different nonparametric variables against each other, either positively or inversely. $P$ value (which is either nonsignificant (NS) if $>0.05$, significant (S) if $<0.05$, or highly significant (HS) if $<0.01$ ) was calculated. The diagnostic accuracy of AFP and SCCA were determined by receiver operator characteristic (ROC) curve analysis, reporting area under the curve (AUC) and its 95\% confidence interval. The diagnostic cut off and the related sensitivity and specificity were determined.

Sensitivity (ability of the test to detect positive cases) = true positive/(true posive + false negative).

Specificity (ability of the test to exclude negative cases) $=$ true negative/(true negative + false positive).

Positive predictive value (PPV) = percent of the true positive to all positive cases.

N egative predictive value (NPV) = percent of the true negative to all negative cases. 


\section{Results}

Age and sex distribution of the studied groups are illustrated in Table 1. Figure 1 illustrates the prominent symptoms in the studied patients. Pattern of hepatitis viruses as well as the risk factors for their acquisition is shown in figure 2 . Findings of the abdominal ultrasound of CLD patients (group A) and HCC patients (group B) are illustrated in Table 2. Figure 3 shows the Child classes of both studied groups, no statistical significant difference was obtained in comparing the two groups together.

The statistical comparison between CLD patients (group A) and HCC patients (group B) regarding serum levels

\begin{tabular}{|c|c|c|c|c|c|}
\hline \multicolumn{6}{|c|}{$\begin{array}{l}\text { Table 1: Demographic data of the studied } \\
\text { groups }\end{array}$} \\
\hline \multirow[t]{2}{*}{ Variable } & \multicolumn{2}{|c|}{$\begin{array}{l}\text { Group A } \\
(\mathrm{n}=30)\end{array}$} & \multicolumn{2}{|c|}{$\begin{array}{l}\text { Group B } \\
(n=49)\end{array}$} & \multirow[t]{2}{*}{$P$ value } \\
\hline & Mean & SD (\%) & Mean & SD (\%) & \\
\hline Age & 49.8 & 11.3 & 56.2 & 8.2 & $<0.05$ \\
\hline Sex & Male & 13 & 43.3 & 39 & 79.6 \\
\hline$<0.01$ & Female & 17 & 56.7 & 10 & 20.4 \\
\hline
\end{tabular}

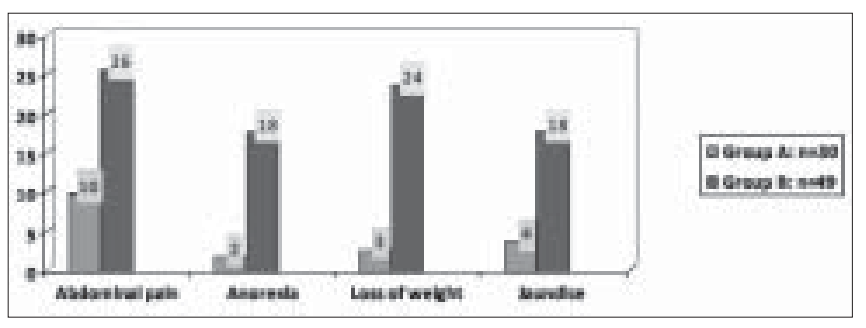

Figure 1: Symptoms of CLD (group A) and HCC (group B)

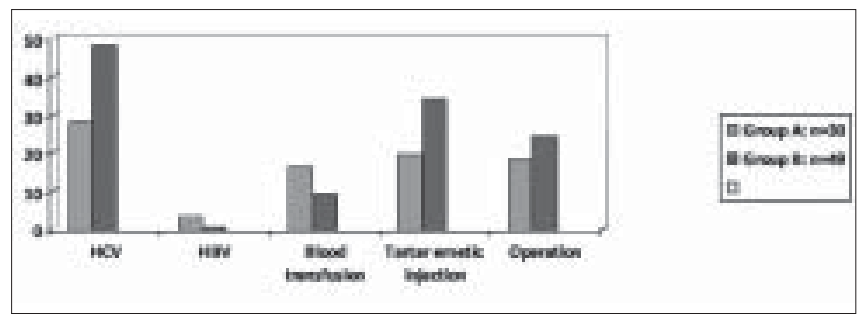

Figure 2: Type of hepatitis viruses and risk factors of its acquisition in both group $A$ and $B$

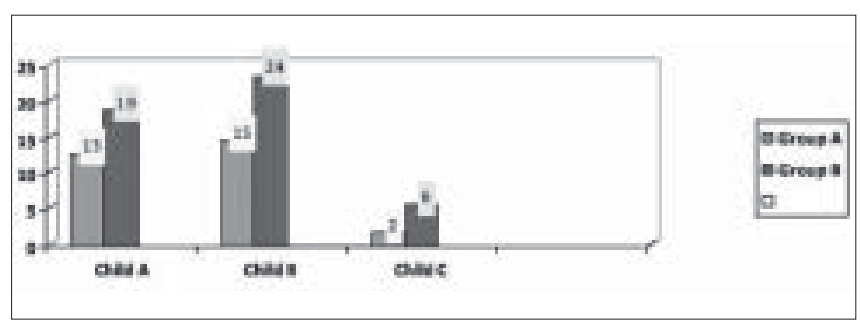

Figure 3: Comparison between both groups as regards Child class of AFP and SCCA is illustrated in Table 3. AFP was higher in group $B(1040.3 \pm 2315.4 \mathrm{ng} / \mathrm{ml})$ than group A $(8.5 \pm 20 \mathrm{ng} / \mathrm{ml})$ with a significant difference in between $(P<0.05)$. SCCA was also higher in group $B(5.1 \pm 7.7 \mathrm{ng} / \mathrm{ml})$ than group A $(1.1 \pm 0.5 \mathrm{ng} / \mathrm{ml})$ with a high statistically significant difference in between $(P<0.01)$.

Table 4 shows that there was a statistically significant difference in the mean level of both AFP and SCCA when comparing all groups together. After statistical revision, positive correlation between serum levels of SCCA and AFP was found but it was very weak, Figure 4.

Table 5 shows the sensitivity, specificity, positive predictive value, and negative predictive value of AFP and squamous cell carcinoma antigen at different cut-off values in relation to diagnosis of HCC determined by ROC curve [Figure 5].

Table 6 shows the relation between SCCA level on one side and the 0 kuda stage and the tumor burden on the other side. No statistical significance was elicited. Pearson correlation between the tumor burden and the level of SCCA showed $r=0.06, P>0.05$.

Table 7 shows that no statistical significant difference of SCCA level in both groups among different Child classes which reflect the severity of the liver disease. Pearson correlation: $r=0.17, \mathrm{P}>0.05$.

Table 2: Statistical comparison between group $A^{*}$ and group $B^{* *}$ based on abdominal ultrasonography findings

\begin{tabular}{|c|c|c|c|c|c|c|}
\hline \multirow{2}{*}{\multicolumn{2}{|c|}{ Variable }} & \multicolumn{2}{|c|}{$\begin{array}{l}\text { Group A } \\
(n=30)\end{array}$} & \multicolumn{2}{|c|}{$\begin{array}{l}\text { Group B } \\
(n=49)\end{array}$} & \multirow[t]{2}{*}{$P$ value } \\
\hline & & No. & $\%$ & No & $\%$ & \\
\hline \multicolumn{2}{|l|}{ Hepatomegaly } & 26 & 86.7 & 33 & 67.3 & $>0.05$ \\
\hline \multicolumn{2}{|l|}{ Coarse liver } & 19 & 63.3 & 49 & 100 & $<0.01$ \\
\hline \multicolumn{2}{|l|}{ Splenomegaly } & 20 & 66.7 & 41 & 83.7 & $>0.05$ \\
\hline \multicolumn{2}{|l|}{ Ascites } & 16 & 53.3 & 25 & 51 & $>0.05$ \\
\hline \multicolumn{7}{|l|}{$\mathrm{HFL}^{* * *}$} \\
\hline $\begin{array}{l}\text { Number of } \\
\text { focal lesions }\end{array}$ & $\begin{array}{c}+ \text { ve } \\
1 \\
2 \\
3 \\
4\end{array}$ & $\begin{array}{l}- \\
- \\
- \\
- \\
-\end{array}$ & $\begin{array}{l}- \\
- \\
- \\
- \\
-\end{array}$ & $\begin{array}{c}49 \\
28 \\
5 \\
3 \\
13\end{array}$ & $\begin{array}{c}100 \\
57.1 \\
10.2 \\
6.1 \\
26.5\end{array}$ & $<0.01$ \\
\hline \multicolumn{2}{|c|}{ Portal vein thrombosis } & 1 & 3.3 & 19 & 38.8 & $<0.01$ \\
\hline
\end{tabular}


Table 3: Statistical comparison between group $A^{\star}$ and group $B^{\star \star}$ based on serum levels of alpha fetoprotein and squamous cell carcinoma antigen

\begin{tabular}{|c|c|c|c|c|c|c|c|}
\hline \multirow[t]{2}{*}{ Variable } & \multicolumn{2}{|c|}{ Group A $(n=30)$} & \multicolumn{2}{|c|}{ Group B $(n=49)$} & \multicolumn{2}{|c|}{ Group C $(n=15)$} & \multirow[t]{2}{*}{$P$ value } \\
\hline & $M$ & SD & M & SD & M & SD & \\
\hline AFP (up to $5.8 \mathrm{ng} / \mathrm{ml}$ ) & 8.5 & 20 & 1040.3 & 2315.4 & 2.2 & 1.4 & $<0.05$ \\
\hline SCCA (up to $1.2 \mathrm{ng} / \mathrm{ml}$ ) & 1.1 & 0.5 & 5.1 & 7.7 & 0.78 & 0.43 & $<0.01$ \\
\hline
\end{tabular}

*Group A, CLD patients; **Group B, HCC patients

Table 4: Statistical comparison of squamous cell carcinoma antigen between group $1^{*}$ and group 2** Variable

\begin{tabular}{lllllll} 
& \multicolumn{2}{c}{$\begin{array}{c}\text { Group 1 } \\
(\mathbf{n}=\mathbf{2 9})\end{array}$} & & \multicolumn{2}{c}{$\begin{array}{c}\text { Group 2 } \\
(\mathbf{n}=\mathbf{2 0})\end{array}$} & P value \\
\cline { 2 - 3 } & Mean & SD & & Mean & SD & \\
\hline SCCA $(\mathrm{ng} / \mathrm{ml})$ & 5.3 & 9 & 4.9 & 5.5 & $>0.05$ \\
\hline${ }^{*} \mathrm{AFP}<200 \mathrm{ng} / \mathrm{ml} ;{ }^{* *} \mathrm{AFP}>200 \mathrm{ng} / \mathrm{ml}$ & & &
\end{tabular}

Table 5: Sensitivity, specificity, positive predictive value, and negative predictive value of alpha fetoprotein and squamous cell carcinoma antigen at different cut-off values in relation to diagnosis of HCC determined by ROC curve*

\begin{tabular}{cccccc}
\hline & $\begin{array}{c}\text { Cut-off } \\
\text { value } \\
(\mathbf{n g} / \mathbf{m l})\end{array}$ & Sensitivity & Specificity & PPV & NPV \\
\hline AFP & 1.5 & 100.0 & 48.9 & 68.1 & 100.0 \\
& 5.0 & 91.8 & 91.1 & 91.8 & 91.1 \\
& 7.7 & $89.8 \%$ & $93.3 \%$ & $93.6 \%$ & 89.4 \\
& 90 & 51.0 & 100.0 & 100.0 & 65.2 \\
& 200 & $40.8 \%$ & $100 \%$ & $100 \%$ & $60.8 \%$ \\
\hline SCCA & 0.3 & $100 \%$ & $6.7 \%$ & $53.8 \%$ & $100 \%$ \\
& 1.5 & $77.6 \%$ & $84.4 \%$ & $84.4 \%$ & $77.6 \%$ \\
& 3.5 & $38.8 \%$ & $100 \%$ & $100 \%$ & $60 \%$ \\
\hline *Patient group B (HCC) $n=49$, control group A (CLD) $n=45$ &
\end{tabular}

Table 6: The relation between squamous cell carcinoma antigen level on one side and the Okuda stage and the tumor burden on the other side

\begin{tabular}{lccccc}
\hline Tumor burden & $\begin{array}{c}\text { Number } \\
\text { of patients }\end{array}$ & \multicolumn{3}{c}{ SCCA $(\mathbf{n g} / \mathbf{m l})$} & $\boldsymbol{P}$ value \\
\cline { 3 - 5 } & Mean & SD & \\
\hline$<50 \%$ of the liver & 25 & 6.2 & 9.9 & $>0.05$ \\
\hline$>50 \%$ of the liver & 24 & 3.9 & 4.2 & \\
\hline Okuda stage & & & & \\
\hline I & 9 & 3.4 & 3.3 & $>0.05$ \\
\hline II & 31 & 5.1 & 8.7 & \\
\hline III & 9 & 6.6 & 7.2 & \\
\hline
\end{tabular}

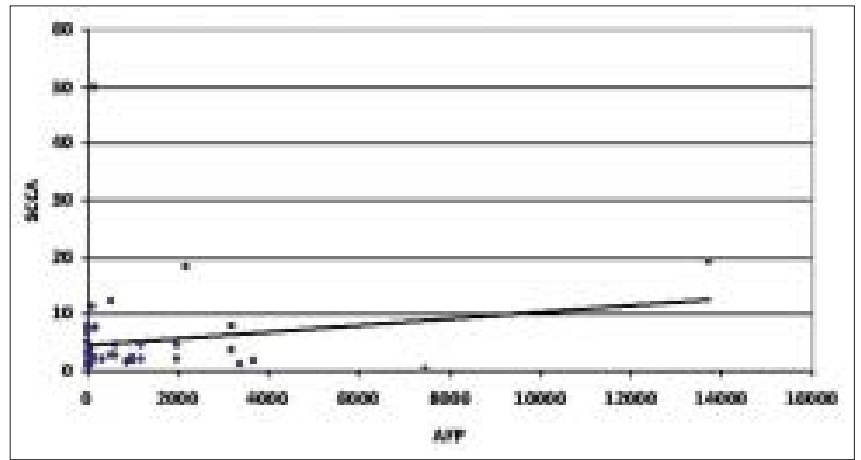

Figure 4: Correlation between serum levels of AFP and SCCA

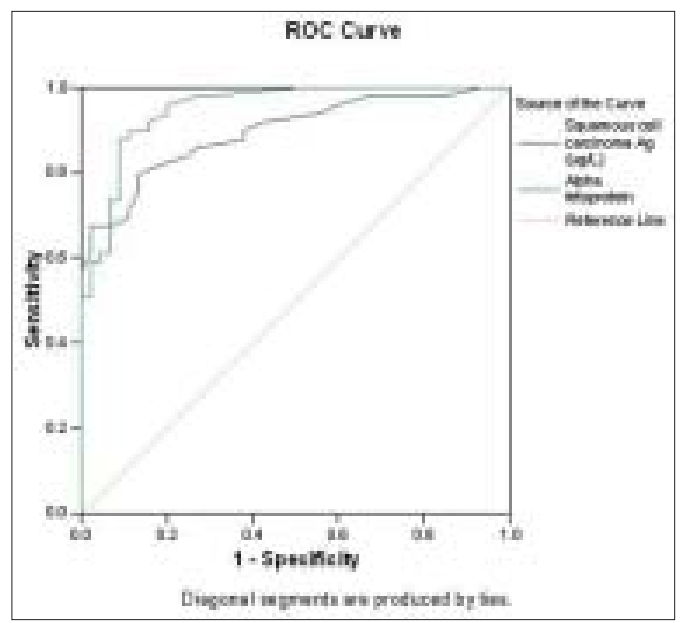

Figure 5: ROC curve showing specificity and sensitivity of SCCA and AFP

Table 7: Squamous cell carcinoma antigen level in both groups among different Child classes which reflect the severity of the liver disease

\begin{tabular}{rccccc}
\hline & & $\begin{array}{c}\text { Number } \\
\text { of patients }\end{array}$ & Mean & $\begin{array}{c}\text { Standard } \\
\text { deviation }\end{array}$ & $\boldsymbol{P}$ value \\
\hline Group A & Child A & 19 & 4 & 3.4 & $>0.05$ \\
\hline & Child B & 24 & 5.3 & 9.8 & \\
\hline & Child C & 6 & 8 & 8.4 & \\
\hline Group B & Child A & 13 & 1 & 0.6 & $>0.05$ \\
\hline & Child B & 15 & 1.2 & 0.3 & \\
\hline & Child C & 2 & 1 & 0.07 & \\
\hline
\end{tabular}




\section{Discussion}

$\mathrm{HCC}$ is the fifth most common malignancy in the world. I ts incidence is increasing worldwide ranging between $3-9 \% \cdot{ }^{[14]}$ The estimated annual number of cases exceeds $500,000 .{ }^{[15]}$

In Egypt, HCC was reported to account for about $4.7 \%$ of $C L D$ patients. ${ }^{[4]}$ Over a decade, there were nearly two-fold increases in proportion of HCC among CLD patients in Egypt with a significant decline in $\mathrm{HBV}$ infection and a slight increase of HCV infection as a risk factor. ${ }^{[5]}$

U nfortunately, surveillance programs are hindered by the poor performance of the commonly used serum markers, namely, AFP, ${ }^{[15]}$ even in combination with abdominal ultrasound. A tremendous amount of effort has been and continues to be applied to the search for improved HCC biomarkers.

This study was conducted to evaluate the clinical usefulness of serum SCCA as a serologic marker for early detection of HCC among high-risk patients and to compare it with AFP as a known biomarker for diagnosis of HCC.

In the present study, the age of patients with CLD ranged from 25-70 years with a mean of $49.7 \pm 11.3$, while that of patients with $\mathrm{HCC}$ was $40-77$ years with a mean of $56 \pm 8.15$ and a high statistical difference in between $(P<0.001)$. This goes with the results of $E I-$ Zayadi et al, ${ }^{[5]}$ who found slight shift of age of patients with $\mathrm{HCC}$ to the younger age group (40-59 years).

Our demographic data showed that there were 13 males $(43.3 \%)$ and 17 (56.7\%) females among patients with CLD, while there was male predominance in patients with HCC (39 patients representing $79.6 \%$, with high statistical difference in between, $P<0.01$ ). This again agrees with EL Zayadi et al, ${ }^{[5]}$ in a series of $1328 \mathrm{HCC}$ cases; they found that HCC is significantly higher in males than females $(77.7 \%$ and $23.3 \%)$, respectively.

AFP was discovered in 1963 by Abelev, and since then, its measurement is the only marker used in clinical practice for serological diagnosis of HCC, although it has questionable reliability. ${ }^{[16]}$ AFP levels could be normal during the early assessment of $\mathrm{HCC}$ growth and even with persistent tumor growth; there may be a spontaneous AFP fall. It also seems that determination of only the serum AFP level is an unreliable indicator in the early detection of $\mathrm{HCC} .{ }^{[17]}$

Regarding AFP, this study showed a significant difference $(P<0.05)$ between patients with HCC, $C L D$, and controls $(1040.29 \pm 2315,8.47 \pm 20.035$, and $2.207 \pm 1.44 \mathrm{ng} / \mathrm{ml}$, respectively). AFP was also higher among patients with HCC compared to patients with CLD with significant difference in between $(P<$ $0.05)$. The AUC of AFP was $0.959(95 \% \mathrm{Cl} 0.896-$ 0.989 ), the cut-off point was established at $7.7 \mathrm{ng} / \mathrm{ml}$ with a sensitivity of $89.8 \%$ and a specificity of $93.3 \%$.

H owever, according to the European Association for the study of the liver (EASL), it is diagnostic above $200 \mathrm{ng} / \mathrm{ml} .^{[15]}$ In the present study, at AFP level of $200 \mathrm{ng} / \mathrm{ml}$, the sensitivity was $40.8 \%$, while the specificity was $100 \%$.

Regarding SCCA, our study detected a highly significant difference $(P<0.001)$ between patients with HCC, CLD, and controls $(5.138 \pm 7.689,1.133 \pm 0.516$, and $0.787 \pm 0.432 \mathrm{ng} / \mathrm{ml}$, respectively). SCCA was also higher among patients with HCC compared to patients with CLD with a highly significant difference in between $(P<0.001)$.

The significant difference between cases and controls as regards the levels of both AFP and SCCA, which is reported in our study, agrees with Giannelli et al, ${ }^{[18]}$ who also recommended the combined use of AFP, SCCA, and immunocomplexed forms of AFP and SCCA increases the accuracy of HCC diagnosis.

In H CC patients, there were 29 patients with AFP < $200 \mathrm{ng} / \mathrm{ml}$ and 20 patients with AFP level $>200 \mathrm{ng} /$ $\mathrm{ml}$. The SCCA level was persistently elevated in both groups ( 5.3 and $4.9 \mathrm{ng} / \mathrm{ml}$, respectively), representing its useful role as a serological marker for diagnosis of HCC patients with normal level of AFP.

Pontisso et al, ${ }^{[10]}$ performed a case control study on 65 patients with HCC and 20 normal livers. SCCA was detected by immunohistochemistry in 55 out of 65 patients' $(85 \%)$ tumor specimens, but none in the 20 controls. There was no significant correlation between SCCA and other clinical and biochemical parameters including age, sex, and transaminases levels and this agrees with the results obtained in this study.

In our study, the AUC of SCCA was 0.869 (95\% $\mathrm{Cl} 0.783-0.929)$, the cut-off value was established at $1.5 \mathrm{ng} / \mathrm{ml}$ with sensitivity of $77.6 \%$ and specificity of $84.4 \%$ ). In the study performed by Giannelli et al, ${ }^{[19]}$ on SCCA combined with AFP on 120 patients with HCC, 90 patients with CLD, and 41 healthy subjects, AFP values in HCC patients and CLD patients were $23.06 \mathrm{IU} / \mathrm{ml}$ and $5.05 \mathrm{IU} / \mathrm{ml}$, respectively, with statistically significant difference in between, while 
mean levels of SCCA were $0.678 \mu \mathrm{g} / \mathrm{L}$ and $0.376 \mu \mathrm{g} / \mathrm{L}$, respectively, which mounted a statistically significant difference, this agrees with our results. The AUC of SCCA was $0.705(95 \% \mathrm{Cl} 0.638-0.766)$, the cut-off point was established at 0.368 with sensitivity of $84.2 \%$ and specificity of $48.9 \%$. The AU C of AFP was 0.717 (95\% Cl 0.651-0.777), the cut-off value was established at $13.7 \mathrm{IU} / \mathrm{ml}$ with sensitivity of $45 \%$ and specificity of $86.7 \%$. The difference between AUC of SCCA and that of AFP was 0.009 with no statistical difference in between. This may be attributed to larger size of their sample.

It is worth mentioning that Beale et $\mathrm{al}^{[20]}$ found that SCCA 1 was not elevated in patients with HCC arising on top of nonalcoholic and alcoholic fatty liver disease which suggests that this HCC marker may be etiology related and so results are different in Egyptian patients as most HCC here arise on top of $\mathrm{HCV}$ and/or H BV liver disease. Also, the choice of optimal biomarkers for HCC surveillance may be determined by the etiology of underlying liver disease.

Data in our study pointed to absence of correlation between the SCCA level, size and burden of the tumor, and severity of CLD, but further studies on larger number of patients are needed to clarify this finding.

\section{Conclusions}

The results of our study suggest that SCCA could represent a useful tool as a marker for detection of $\mathrm{HCC}$ and for differential diagnosis between HCC and cirrhosis as we found that the levels of SCCA are significantly higher in patients with HCC than in CLD patients and controls.

Recommendations: M ore studies on a large scale are needed to assess the diagnostic as well as the prognostic value of SCCA in patients with HCC with different etiologies of liver disease. Also, multivariate analytical studies are needed to evaluate various clinical, laboratory, and radiological parameters to improve the diagnostic accuracy for early detection of HCC.

\section{References}

1. El-Serag HB, Davila JA, Petersen NJ, and McGlynn KA. The continuing increase in the incidence of hepatocellular carcinoma in United States: An update. Ann Intern Med 2003;139:817-23.

2. El-Bokainy NM. Epidemiology of cancer. In: El-Bokainy NM, editor.
General Pathology, vol. 47. Al-Asdekaa Graphics Center; 1998. p. 77.

3. Shamaa S, El-Bedawy AF, Azzam F, Hamed M, Shehab EI-Din M, Attia M. Hepatocellular carcinoma in Egypt. J Egypt Nat Can Inst 1992;4:761-72.

4. El-Zayadi A, Abaza H, Shawky S, Mohamed MK, Selim OE, Badran HM. Prevalence and epidemiological features of hepatocellular carcinoma in Egypt: A single center experience. Hepatol Res 2001;19:170.

5. El-Zayadi AR, Badran HM, Barakat EM, Attia Mel-D, Shawky S, Mohamed MK, et al. Hepatocellular carcinoma in Egypt: A single center study over a decade. World J Gastroenterol 2005;11:5193-8.

6. Sangiovanni A, Del Ninno E, Fasani P, De Fazio C, Ronchi G, Romeo $\mathrm{R}$, et al. Increased survival of cirrhotic patients with a hepatocellular carcinoma detected during surveillance. Gastroenterology 2004; 126:1005-14.

7. Colombo M. Screening for cancer in viral hepatitis. Clin Liver Dis 2001;5: 109 .

8. Okuda K, Kondo Y, Nakano M, Kage M, Arakawa M, Kojiro M, et al. Hepatocellular carcinoma presenting with pyrexia and leukocytosis: Report of five cases. Hepatology 1991;13:695-700.

9. Kato H, Suehiro Y, Morioka H, Torigoe T, Myoga A, Sekiguchi K, et al. Heterogeneous distribution of acidic TA-4 in cervical squamous cell carcinoma: Immunohistochemical demonstration with monoclonal antibodies. Jpn J Cancer Res 1987;78:1246-50.

10. Pontisso $\mathrm{P}$, Calabrese F, Benvegnù L, Lise M, Belluco C, Ruvoletto MG, et al. Overexpression of squamous cell carcinoma antigen variants in hepatocellular carcinoma. Br J Cancer 2004;90:833.

11. Sturgeon C. Practice guidelines for tumor marker use in the clinic. Clin Chem 2002;48:1151-9.

12. Bruix J, Sherman M. Management of hepatocellular carcinoma. Hepatology 2005;5: 1208-36.

13. Vassilakopoulos T, Troupis T, Sotiropoulou C, Zacharatos P, Katsaounou P, Parthenis D, et al. Diagnostic and prognostic significance of squamous cell carcinoma antigen in non-small cell lung cancer. Lung Cancer 2001;32:137.

14. El-Serag HB. Hepatocellular carcinoma: an epidemiologic view. J Clin Gastroenterol 2002;35:S72.

15. Bruix J, Sherman M, Llovet JM, Beaugrand M, Lencioni R, Burroughs AK, et al. Clinical management of hepatocellular carcinoma: Conclusions of the Barcelona-2000 EASL conference; European Association for the Study of the Liver. J Hepatol 2001;35:421-30.

16. Trevisani F, D'Intino PE, Morselli-Labate AM, Mazzella G, Accogli E, Caraceni P, et al. Serum alpha-fetoprotein for diagnosis of hepatocellular carcinoma in patients with chronic liver disease: Influence of HBsAg and anti-HCV status. J Hepatol 2001;34:570-5.

17. El-Zayadi A, El-Okby S, Shaker M, Dabbous H. Correlation between alphafetoprotein levels and volume of the hepatocellular carcinoma. J Egypt Assoc Immunol 1995;2:97-100.

18. Giannelli G, Fransvea E, Trerotoli P, Beaugrand G, Marinosci F, Lupo $L$, et al. Clinical validation of combined serological biomarkers for improved hepatocellular carcinoma diagnosis in 961 patients. Clin Chim Acta 2007;383:147-52.

19. Giannelli G, Marinosci F, Trerotoli P, Volpe A, Quaranta M, Dentico $\mathrm{P}$, et al. SCCA antigen combined with alpha-fetoprotein as serologic markers of HCC. Int J Cancer 2005; 117:506-9.

20. Beale G, Chattopadhyay D, Gray J, Stewart S, Hudson M, Day C, et al. AFP, PIVKAII, GP3, SCCA-1 and follisatin as surveillance biomarkers for hepatocellular cancer in non-alcoholic and alcoholic fatty liver disease. BMC Cancer 2008;8:200.

Source of Support: Nil, Conflict of Interest: None declared. 